\title{
Strongly sheared stratocumulus convection: an observationally based large-eddy simulation study
}

\author{
S. Wang ${ }^{1}$, X. Zheng ${ }^{2}$, and Q. Jiang ${ }^{1}$ \\ ${ }^{1}$ Naval Research Laboratory, Monterey, CA, USA \\ ${ }^{2}$ RSMAS, University of Miami, Miami, FL, USA \\ Correspondence to: S. Wang (wang@nrlmry.navy.mil) \\ Received: 2 February 2012 - Published in Atmos. Chem. Phys. Discuss.: 13 February 2012 \\ Revised: 28 May 2012 - Accepted: 29 May 2012 - Published: 14 June 2012
}

\begin{abstract}
Unusually large wind shears across the inversion in the stratocumulus-topped marine boundary layer (MBL) were frequently observed during VOCALS-REx. To investigate the impact of wind shear on the MBL turbulence structure, a large-eddy simulation (LES) model is used to simulate the strongly sheared MBL observed from Twin-Otter RF 18 on 13 November 2008. The LES simulated turbulence statistics agree in general with those derived from the measurements, with the MBL exhibiting a decoupled structure characterized by an enhanced entrainment and a turbulence intensity minimum just below the clouds. Sensitivity simulations show that the shear forcing tends to reduce the dynamic stability of the inversion, characterized by the bulk (or gradient) Richardson number. This decrease enhances the entrainment mixing, leading to reduced cloud water. Consequently, the turbulence intensity in the MBL is significantly weakened by the intense wind shear. The inversion thickens considerably and the MBL top separates from the cloud top, creating a finite cloud-free sublayer of $10-50 \mathrm{~m}$ thickness within the inversion, depending on the Richardson number. The weakened inversion tends to enhance the turbulence buoyant consumption and simultaneously lead to a reduced buoyant production in the cloud layer due to less radiative cooling. These effects may result in a decoupling process that creates the different heating/moistening rates between the cloud and subcloud layer, leading to a two-layered structure in the strongly sheared stratocumulus-topped MBL.
\end{abstract}

\section{Introduction}

VOCALS-REx (Variability of the American Monsoons Ocean-Cloud-Atmosphere-Land Study-Regional Experiment) took place off the west coast of Chile/Peru in the Southeast Pacific during October and November 2008. Two primary focuses of the field campaign are: (1) the aerosol-cloud-precipitation interaction in stratocumulus clouds; and (2) the coupled ocean-atmosphere-land system in the Southeast Pacific. Comprehensive measurements were made on many platforms including aircrafts, ships, buoys, and land-based instruments. Wood et al. (2011) gave a comprehensive review regarding the objectives, scope, and specific operations of VOCALS-REx.

One of the most persistent features of the stratocumulustopped MBL observed during VOCALS-REx is the unusually intense wind shear across the inversion. Averaged soundings along $20^{\circ} \mathrm{S}$ using aircraft measurements as well as rawindsondes launched from the $R$. H. Brown Research Vessel clearly exhibit an approximate -4 to $-7 \mathrm{~ms}^{-1}$ and $4 \mathrm{~m} \mathrm{~s}^{-1}$ to $6 \mathrm{~m} \mathrm{~s}^{-1}$ jump across the inversion in the meridional and zonal wind component, respectively (Bretherton et al., 2010; Wang et al., 2011; Zheng et al., 2011). The shear was frequently accompanied with a wind speed maximum just below the inversion. Unlike many other boundary layers where the shear is mainly a result of surface friction, the shear documented during VOCALS-REx is primarily caused by baroclinicity within the inversion, which is linked to the large-scale horizontal gradient of the inversion height (Bretherton et al., 2010; Wang et al., 2011). Perhaps for this reason, the wind shear tends to be unusually intense and persistent. 
An example of the sheared MBL is exhibited in Fig. 1, which shows two similar soundings taken during the TwinOtter research flight 18 (RF18) near $72^{\circ} \mathrm{W}$ and $20^{\circ} \mathrm{S}$ on 13 November 2008. A sharp temperature inversion caps the cloud layer with $\sim 10 \mathrm{~K}$ jump in liquid water potential temperature $\theta_{1}$ and $-2.6 \mathrm{~g} \mathrm{~kg}^{-1}$ jump in total water mixing ratio $q_{\mathrm{t}}$. The liquid water mixing ratio $\left(q_{\mathrm{c}}\right)$ reaches its maximum value $\left(\sim 0.3 \mathrm{~g} \mathrm{~kg}^{-1}\right)$ near the cloud top. An intense wind shear is present across the inversion; the meridional wind component $(v)$ changes sharply from $0 \mathrm{~m} \mathrm{~s}^{-1}$ to $-9 \mathrm{~m} \mathrm{~s}^{-1}$, whereas the zonal component $(u)$ changes only about $4 \mathrm{~m} \mathrm{~s}^{-1}$. The wind variations within the boundary layer are significantly smaller than those across the inversion.

Wind shear across the inversion is well known for its significant role in generating turbulent mixing and enhancing the entrainment rate in cloud-free convective boundary layers. For example, the shear is found to enhance the entrainment heat flux by producing Kelvin-Helmholtz wave like billows within the entrainment zone (Kim et al., 2003). The thickness of the layer is controlled by a balance among the shear generation, buoyancy consumption, and dissipation of turbulence kinetic energy (TKE) (Conzemius and Fedorovich, 2006). This balance is manifested by an equilibrium Richardson number of the layer that is close to the critical value 0.25 (Turner, 1973; Conzemius and Fedorovich, 2006).

When the wind shear occurs at the stratocumulus cloud top, its effects are considerably more complex due to the interplay among the turbulent mixing, radiation and cloud water evaporation. The turbulent mixing driven by the wind shear may lead to local dissipation of clouds, as suggested by de Roode and Wang (2007) based on analysis of turbulence data. A few model simulations, including large-eddy simulation (LES) studies, examine the overall turbulence and inversion characteristics in presence of wind shear. The reduction of cloud water due to the shear enhanced mixing may significantly decrease the longwave cooling rate near cloud top, leading to considerable weakening of the turbulence intensity (Chen and Cotton, 1987; Wang et al., 2008). Because of shear-enhanced mixing, a turbulent and unsaturated sublayer of several tens of meters may form just above clouds within the inversion (Moeng et al., 2005; Wang et al., 2008). The thickness of this sublayer can be further linked to the mean shear strength (Wang et al., 2008). These broad features of the simulated shear mixing were confirmed by a few observational studies (e.g., Brost et al., 1982; Katzwinkel et al., 2011). After analyzing the high-resolution turbulence measurements within the inversion layer, Katzwinkel et al. (2011) suggests that presence of the turbulent and cloud-free layer may reduce the evaporation since moister and cooler air, relative to the non-turbulent air above the inversion, is entrained into clouds.

The research on turbulence dynamics of stratocumulus clouds has been generally focused on the interaction among the turbulence buoyant production, the cloud-top entrain-
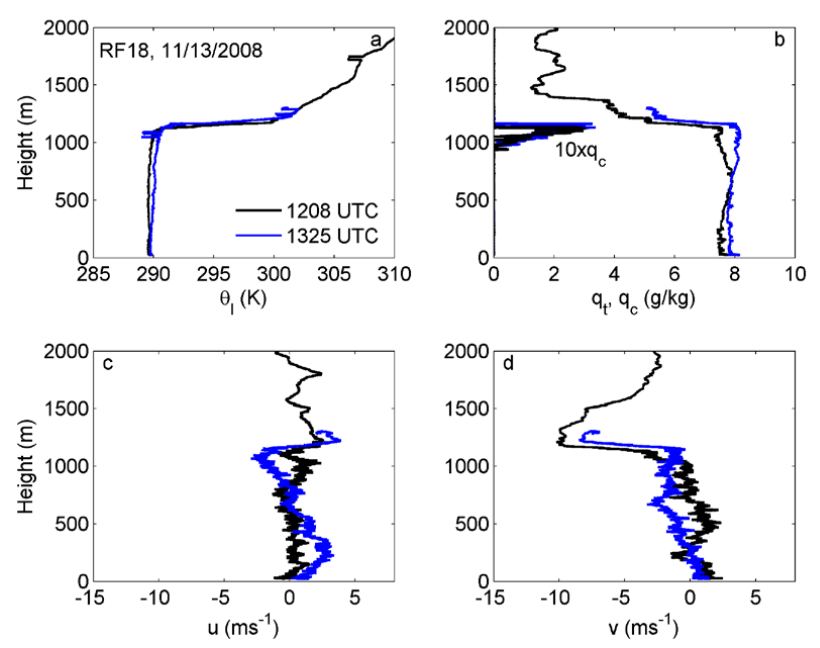

Fig. 1. Soundings taken near $72^{\circ} \mathrm{W}$ and $20^{\circ} \mathrm{S}$ during Twin-Otter RF18, 13 November 2008. (a) Liquid water potential temperature $\left(\theta_{1}\right)$; (b) total water mixing ratio $\left(q_{\mathrm{t}}\right)$ and cloud water mixing ratio $\left(q_{\mathrm{c}}\right)$; (c) $u$; and (d) $v$. Following definitions are applied for the thermodynamic variables: $\theta_{\mathrm{l}}=\theta-L \theta /\left(T c_{\mathrm{p}}\right) \cdot q_{\mathrm{c}}$ and $q_{\mathrm{t}}=q_{\mathrm{v}}+q_{\mathrm{c}}$, where $\theta$ is potential temperature and $q_{\mathrm{v}}$ water vapor mixing ratio.

ment, and the large-scale meteorological conditions (e.g., Lilly, 1968; Nicholls et al., 1984; Bretherton et al., 1997; and Stevens, 2000). For example, one specific issue that has drawn much attention is about decoupling in the cloudtopped MBL, a process that tends to create different heating/moistening rates between the cloud and subcloud layer, leading to a two-layered structure (e.g., Nicholls et al., 1984). In these studies, roles of the shear have been rarely examined. Although the importance of the shear has been recognized in a few studies including those highlighted above, many questions remain unanswered. How does the shear affect the entrainment zone structure? Does it affect the entrainment rate? What impact does it have on the decoupling?

This study focuses on the observed case of the sheared stratocumulus convection presented in Fig. 1. LES model simulations and observations are used to address questions highlighted above. We will first provide descriptions of the LES model and simulation setups in Sect. 2 and discuss the overall turbulence structure, including evaluation of the model results using observations in Sect. 3. Further examination of the turbulent mixing in the entrainment zone and on the impact of the shear on the entrainment and decoupling will be presented in Sects. 4 and 5, respectively. Section 6 summarizes the work.

\section{LES model description and simulation setup}

We use Naval Research Laboratory Coupled Ocean/Atmosphere Mesoscale Prediction System-LargeEddy Simulation (COAMPS-LES) model in this study 
(Golaz et al, 2005). Readers are referred to the paper for detailed description. Briefly, the anelastic approximation is assumed for efficient numerical computation; Deardorff's prognostic turbulence kinetic technique is used for the subgrid-scale model (Deardorff, 1980); Bott positive definite advection scheme is applied to scalar advection (Bott, 1989); the four stream Fu-Liou radiation parameterization is used for both longwave and shortwave computation (Fu and Liou, 1992); a saturation adjustment scheme is used for the condensation and evaporation; and the precipitation processes are deactivated. At the top of the domain, a constant gradient condition is applied to all variables. The lateral boundary conditions are periodic. The model uses $281 \times 281$ grid points in horizontal with a uniform spacing $\Delta x=\Delta y=25 \mathrm{~m}$. A vertically stretched grid $(\Delta z)$ is designed to provide minimum grid spacing of $5 \mathrm{~m}$ within the inversion and gradually increased spacing to $25 \mathrm{~m}$ below and above the inversion. The grid system spans a volume of $7 \times 7 \times 2 \mathrm{~km}$. The time step is 0.5 to $0.75 \mathrm{~s}$. The choice of the resolution is, in part, based on our previous experience described in Wang et al. (2008) where a grid mesh of $10 \times 10 \times 5 \mathrm{~m}(\Delta x \times \Delta y \times \Delta z)$ produced a very similar turbulence structure to that of $30 \times 30 \times 5$-to- $20 \mathrm{~m}$ for a strongly sheared stratocumulus case. It is also consistent with the resolutions used for a number of LES case studies (e.g., Stevens et al., 2005; Golaz et al., 2005).

The surface turbulent fluxes in the simulations are specified using values calculated from the turbulence measurements made at the lowest level $(\sim 30 \mathrm{~m})$ during RF18; they are listed in Table 1. Large-scale vertical motion changes linearly with the specified divergence below the boundary layer height and then remains at its $z_{\mathrm{i}}$ value for all levels above. To keep the free atmospheric structure from departing significantly from the observation due to the subsidence and radiation, we applied a nudging term to all the variables above the inversion top with a time scale of $4 \mathrm{~h}$. Simulation experiments showed that our results are not sensitive to the choice of this time scale.

Large-scale shear forcing, i.e., the thermal wind profile, is an essential aspect of the large-scale environment as it defines magnitude of the wind shear for the simulations. We calculated daily averaged mean geostrophic winds for 13 November 2012 from COAMPS real-time forecast (Wang et al., 2011), which are plotted using a normalized MBL height in Fig. 2a. The meridional component $\left(V_{\mathrm{g}}\right)$ changes from $1 \mathrm{~m} \mathrm{~s}^{-1}$ below the inversion to $-10 \mathrm{~m} \mathrm{~s}^{-1}$ just above it, which is consistent with the jump in the observed wind. The zonal component $\left(U_{\mathrm{g}}\right)$ changes significantly less across the inversion. These mesoscale model results clearly demonstrate that the observed wind shear is directly linked to the large-scale horizontal temperature gradient. Based on both the observations and the regional model results, we specify the geostrophic forcing as shown in Fig. 2b. Three large-scale shear forcings are applied in the study. The strong shear forcing (SS) corresponds to the observed strong shear case; weak
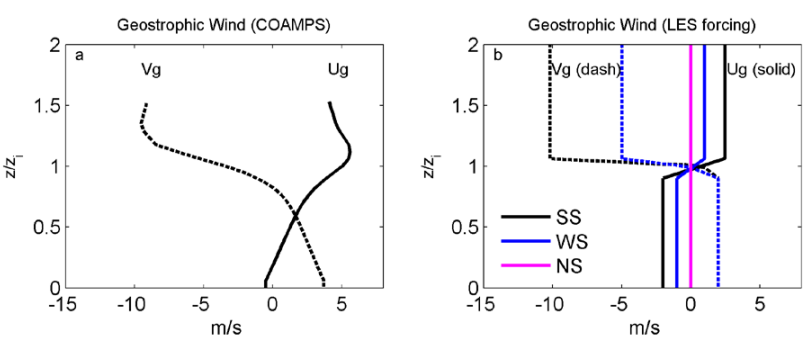

Fig. 2. Specification of geostrophic wind for LES simulations. (a) Daily averaged geostrophic winds on 13 November 2008, derived from the COAMPS regional forecast (Wang et al., 2010); and (b) specified geostrophic winds for simulations. Dashed lines denote meridional components, solid zonal components.

shear forcing (WS) is designed to reduce the SS by one half; no shear forcing (NS) sets mean wind speed to zero.

The initial conditions for $\bar{\theta}_{1}$ and $\bar{q}_{\mathrm{t}}$ are specified according to the soundings at 12:08 UTC. Preliminary simulations indicate that an initially large wind shear leads to rapid cloud dissipation because the shear results in a peak in the turbulent mixing at the cloud top before a quasi-equilibrium between the turbulence and large-scale forcing is established. Therefore, we initialize the wind with constant profiles using values of $\left(U_{\mathrm{g}}, V_{\mathrm{g}}\right)$ above the MBL. Then the wind is nudged toward the geostrophic wind with a time scale of one hour. The nudging term is deactivated after the first hour of the simulation; the wind is then slowly adjusted toward the geostrophy while the turbulence gradually reaches equilibrium with the specified large-scale and surface conditions.

To evaluate the simulations against the observations and analyze the sensitivity to the shear forcing, we perform three simulations with solar radiation processes included. These simulations apply three different large-scale shear forcings as shown in Fig. 2b. To isolate the shear impact, we also conduct another set of three simulations in which the solar radiation is deactivated. The large-scale divergence and surface fluxes are specified according to Table 1. All simulations start at 02:00 LT and end at 10:00 LT and are listed in Table 1 for reference.

\section{Synopsis of turbulence structure}

This section focuses on effects of the shear on the MBL by comparing three simulations (i.e., SS, WS and NS) and evaluating the results using aircraft measurements. Because most of the measurements were made between 07:00 LT and 10:00 LT, all the LES profiles presented here are averaged between these two times with a sampling rate of $30 \mathrm{~s}$. The LES time series are formed by taking averages every minute with this sampling rate. It should be noted that among all the LES runs, the large-scale conditions used in SS should best represent the observed MBL environment. Therefore, 
Table 1. Simulation conditions and results based on last $3 \mathrm{~h}$ averages.

\begin{tabular}{|c|c|c|c|c|c|c|c|c|c|c|c|}
\hline Runs & \multicolumn{2}{|l|}{$\begin{array}{l}\text { Shear } \\
\text { Condition }\end{array}$} & \multicolumn{2}{|c|}{$\begin{array}{l}\text { Surface } \\
\text { conditions }\end{array}$} & $\begin{array}{l}\text { Solar } \\
\text { radiation }\end{array}$ & $\begin{array}{l}\Delta z_{\mathrm{i}} \\
(\mathrm{m})\end{array}$ & $R_{\mathrm{ib}}$ & \multicolumn{2}{|c|}{$\begin{array}{l}w_{\mathrm{e}} \\
\left(\mathrm{mm} \mathrm{s}^{-1}\right)\end{array}$} & $-\Delta F_{\theta} / \Delta F_{\mathrm{R}}$ & $A$ \\
\hline SS & \multicolumn{2}{|l|}{ Strong (obs)/Baroclinic } & \multicolumn{2}{|c|}{ Specified below } & Yes & 92 & 0.34 & 5.4 & & na & 0.38 \\
\hline WS & \multicolumn{2}{|l|}{ Weak/Baroclinic } & \multicolumn{2}{|l|}{ below } & Yes & 35 & 0.61 & 2.5 & & na & 0.14 \\
\hline NS & \multicolumn{2}{|l|}{ No mean wind } & \multicolumn{2}{|l|}{ below } & Yes & 30 & na & 1.8 & & na & 0.066 \\
\hline SSN & \multicolumn{2}{|l|}{ Same as SS } & \multicolumn{2}{|l|}{ below } & No & 90 & 0.37 & 7.6 & & 1.2 & 0.39 \\
\hline WSN & \multicolumn{2}{|l|}{ Same as WS } & \multicolumn{2}{|l|}{ below } & No & 37 & 0.71 & 5.5 & & 0.9 & 0.060 \\
\hline NSN & \multicolumn{2}{|l|}{ Same as NS } & \multicolumn{2}{|l|}{ below } & No & 30 & na & 3.9 & & 0.6 & 0.014 \\
\hline \multirow[t]{4}{*}{ FSN } & \multicolumn{2}{|c|}{ Weak $/ V_{\mathrm{g}}=8 \mathrm{~m} \mathrm{~s}^{-1}, U_{\mathrm{g}}=0.0$} & below ex & ept stress $=0.07 \mathrm{Nm}^{-2}$ & No & 35 & 1.16 & 4.6 & & 0.8 & 0.034 \\
\hline & \multicolumn{10}{|c|}{ Surface conditions and simulation hours } & \\
\hline & $\begin{array}{l}\text { Surface stress } \\
\left(\mathrm{N} \mathrm{m}^{-2}\right)\end{array}$ & \multicolumn{2}{|c|}{$\begin{array}{l}\text { Latent heat flux } \\
\left(\mathrm{W} \mathrm{m}^{-2}\right)\end{array}$} & $\begin{array}{l}\text { Sensible heat flux } \\
\left(\mathrm{W} \mathrm{m}^{-2}\right)\end{array}$ & $\begin{array}{l}\text { Divergence } \\
\left(s^{-1}\right)\end{array}$ & \multicolumn{3}{|c|}{$\begin{array}{l}\text { Surface pressure } \\
(\mathrm{hPa})\end{array}$} & \multicolumn{2}{|c|}{$\begin{array}{l}\text { Simulation } \\
\text { hours (LT) }\end{array}$} & \\
\hline & 0.014 & 30.4 & & 7.2 & $4.0 \times 10^{-6}$ & 1013 & & & $02:($ & 10:00 & \\
\hline
\end{tabular}

the evaluation with observations is mainly focused on the SS simulation.

As shown in Fig. 3, the simulated mean liquid water potential temperature $\left(\bar{\theta}_{\mathrm{l}}\right)$ and total water mixing ratio $\left(\bar{q}_{\mathrm{t}}\right)$ are very similar for all three simulations and comparable with the observations from both the aircraft leg-averages and soundings. Liquid water mixing ratio $\left(\bar{q}_{\mathrm{c}}\right)$ from SS is the smallest among three cases. Its maximum value is $0.26 \mathrm{~g} \mathrm{~kg}^{-1}$, which is smaller than the $q_{\mathrm{c}}$ maximum of $0.32 \mathrm{~g} \mathrm{~kg}^{-1}$ from the sounding shown in Fig. 1b, but larger than the flight horizontal leg-averaged value of $0.2 \mathrm{~g} \mathrm{~kg}^{-1}$. The SS simulated $\bar{v}$ has a $-9.0 \mathrm{~m} \mathrm{~s}^{-1}$ jump across the inversion and reaches values close to zero near the surface, which is consistent with the sounding. Its in-cloud value is $-0.5 \mathrm{~m} \mathrm{~s}^{-1}$ compared to the flight leg averaged $-2.0 \mathrm{~m} \mathrm{~s}^{-1}$. The simulated $\bar{u}$ is about $5 \mathrm{~m} \mathrm{~s}^{-1}$ in the mixed layer from SS and then reduces to the geostrophic wind above the inversion, leading to a $-3 \mathrm{~m} \mathrm{~s}^{-1}$ jump across the inversion compared to the observed shear with a similar amount but in the different direction. The inconsistency in the shear direction in $\bar{u}$ is caused by an initial large geostrophic imbalance in $\bar{v}$, which contributes to a substantial acceleration of $\bar{u}$. The $\bar{u}$ shear, however, is significantly less than the $\bar{v}$ shear.

All three simulated ${\overline{w^{\prime}}}^{2}$ profiles have a similar shape with a local minimum just below the cloud base at $850 \mathrm{~m}$, which in general is consistent with that derived from the observations as shown in Fig. 3d. The SS ${\overline{w^{\prime}}}^{2}$, however, compares better with the observed because its values match closely the observation in terms of the minimum below clouds and maximum near the cloud top. All the simulated buoyancy fluxes compare favorably with the observations. In particular, the diminished buoyancy flux below the cloud base agrees well with the corresponding minimum in the observation, which explains the local minimum values of ${\overline{w^{\prime}}}^{2}$ just below the clouds. It is noteworthy that the observed ${\overline{w^{\prime}}}^{2}$ is also consistent with those derived from other flights in terms of vertical profile as well as magnitude as shown in Zheng et al. (2011). The decrease in positive $\rho_{0} C_{\mathrm{p}} \overline{w^{\prime} \theta_{\mathrm{v}}^{\prime}}$ with the increasing shear forcing is the main reason why the overall magnitude of ${\overline{w^{\prime}}}^{2}$ decreases from the case NS to SS. The shear enhanced mixing reduces $\bar{q}_{\mathrm{c}}$ in SS and WS (Fig. $3 \mathrm{~b}$ ), resulting in a considerable decrease in the radiative cooling compared with that in NS (Fig. 3f). This is a primary reason why the positive $\rho_{0} C_{\mathrm{p}} \overline{w^{\prime} \theta_{\mathrm{v}}^{\prime}}$ in cloud layer decreases with increasing wind shear forcing.

The turbulence intensity minimum just below clouds tends to result in different gradients of turbulent fluxes of conserved variables (e.g., $q_{\mathrm{t}}$ ) between the cloud and subcloud. Consequently, the cloud layer evolves differently from the subcloud layer, leading toward a layered or decoupled MBL structure. This decoupling process plays an important role in the diurnal variation (Turton and Nicholls, 1987) and the stratocumulus-shallow cumulus regime transition (Bretherton et al., 1997).

The total momentum flux, defined by $\sqrt{\overline{w^{\prime} u^{\prime}}+\overline{w^{\prime} v^{\prime}}}$, from the simulation SS agrees well with the observations with a maximum near the cloud top and a local minimum just below the cloud (Fig. 3g). Although the WS simulation has the correct shape of the momentum flux profile, its maximum value is significantly less than the observation. The large momentum flux near the MBL top reflects the effect of the wind shear, because the flux is directly linked to the shear. The minimum values below clouds are also related to the minimum in $\bar{w}^{\prime}$ at those levels. Since the mean wind speed is close to zero in NS, the simulated momentum flux does not resemble any of the features exhibited in the observation.

Both the SS and WS simulated total water fluxes $\left(\rho_{0} L \overline{w^{\prime} q_{\mathrm{t}}^{\prime}}\right)$ have the local minimum values near the cloud base and maximum near the cloud top, features consistent with the observation, although their magnitudes are significantly larger (Fig. 3h). Once again, both the observed and two shear-case simulated $\rho_{0} L \overline{w^{\prime} q_{\mathrm{t}}^{\prime}}$ clearly demonstrate a 

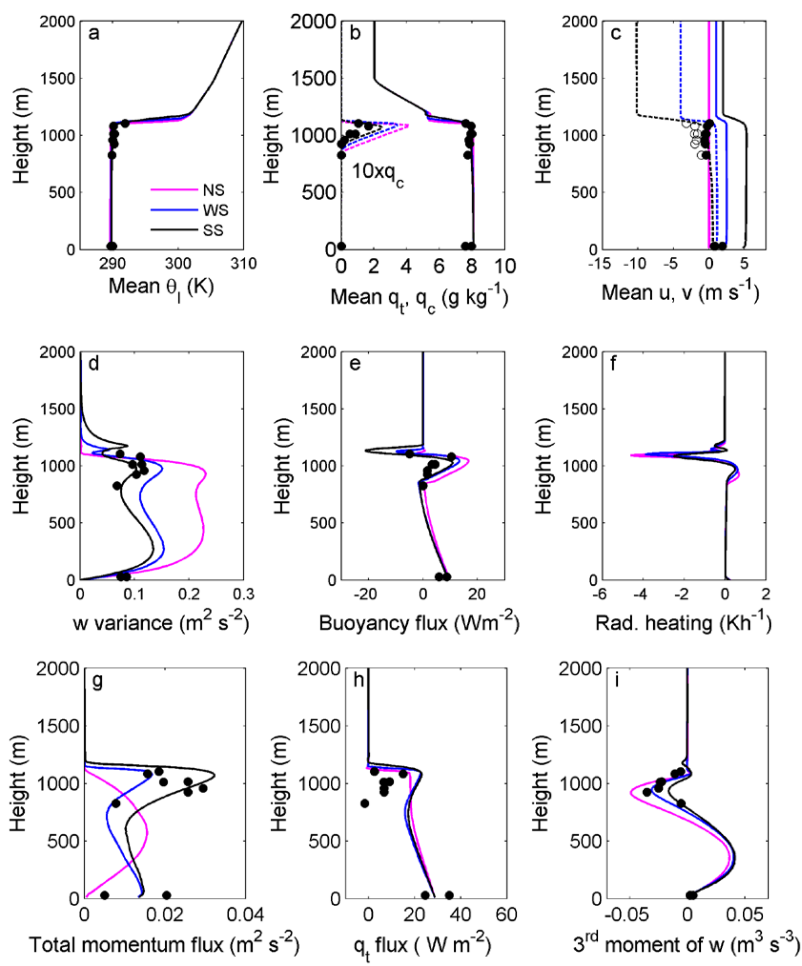

Fig. 3. LES simulated and observationally derived mean and turbulence variables. Solid or dashed lines denote the simulated results; the circles are the leg averaged values derived from measurements. (a) $\bar{\theta}_{\mathrm{l}}$; (b) $\bar{q}_{\mathrm{t}}$ or $\bar{q}_{\mathrm{c}}$; (c) $\bar{u}$ (solid) and $\bar{v}$ (dashed), the solid and open circles are for observed $\bar{u}$ and $\bar{v}$, respectively; (d) ${\overline{w^{\prime}}}^{2}$; (e) $C_{\mathrm{p}} \rho_{0} \overline{w^{\prime} \theta_{\mathrm{v}}^{\prime}}$; (f) radiative heating rate; (g) total momentum flux; (h) $\overline{q^{\prime 2}} ;$; (i) $\overline{w^{\prime 3}}$.

strong decoupling signature of drying in the upper and moistening in the lower portion of the MBL.

The third-moments of $w\left({\overline{w^{\prime}}}^{3}\right)$ of all simulations (Fig. 3i) are negative in the cloud layer, consistent with the observations. The observationally derived values are in general between those of NS and SS; its largest value is $-0.035 \mathrm{~m}^{3} \mathrm{~s}^{-3}$ compared with the corresponding simulated value $-0.05 \mathrm{~m}^{3} \mathrm{~s}^{-3}$ of $\mathrm{NS},-0.031 \mathrm{~m}^{3} \mathrm{~s}^{-3}$ of $\mathrm{WS}$ and $-0.016 \mathrm{~m}^{3} \mathrm{~s}^{-3}$ of SS. The variable ${\overline{w^{\prime}}}^{3}$ is closely linked to the turbulence structure and organization. That is, the negative values imply that narrow and strong downdrafts dominate, and vice versa for the positive values. Golaz et al. (2005) analyze ${\overline{w^{\prime}}}^{3}$ budget using LES simulations; they conclude that negatively skewed $w$ field in stratocumulus clouds is caused by the negatively buoyant downdrafts that are driven by the radiative as well as evaporative cooling (Nicholls, 1989; and Yamaguchi and Randall, 2012). For NS, the large liquid water results in strong radiative cooling, leading to larger negative values of ${\overline{w^{\prime}}}^{3}$.
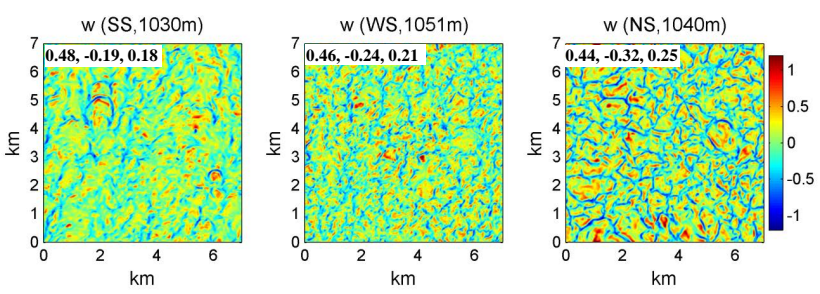

Fig. 4. Plan view of $w^{\prime}$ at the maximum buoyancy level at 09:00 LT for each simulation. Left panel is for SS, center WS, and right NS. To estimate the quantitative changes in the characteristics of updrafts $\left(w^{\prime}>0\right)$ and downdrafts $\left(w^{\prime}<0\right)$, the fractional area and averaged vertical velocities are calculated and shown on the upper-left corner. The first number is for downdraft fraction area, the second the averaged downdraft velocity, and the third the averaged updraft.

The difference in $\overline{w^{\prime 3}}$ among simulations can also be viewed in Fig. 4, which compares the $w$ horizontal distribution among the cases at the levels of maximum buoyancy flux. For all three $w$ fields, the downdrafts are more intense and narrower than the updrafts, consistent with the negatively skewed $w$ in cloud layers for all cases. To demonstrate this feature quantitatively, characteristics of updrafts and downdrafts are calculated and included in the upper-left corner in Fig. 4. The narrower (broader) and stronger (weaker) downdrafts (updrafts) are clearly indicated. The contrast in the characteristics between up- and downdrafts increases with decreasing shear forcing. It is also seen that the turbulence is better organized by strong downdrafts in NS relative to the two shear cases, which is consistent with large negative values of $\overline{w^{\prime 3}}$ in NS. The strong shear forcing case SS appears to have the least organized cellular structure.

To provide a more quantitative comparison, the LES results and observations are averaged using values at the flight levels of horizontal legs within the cloud layer; they are presented in Table 2. As shown in Fig. 3 and Table 2, the SS simulated MBL compares better than others in terms of the mean thermal profiles and the 2nd-moment turbulence variables such as ${\overline{w^{\prime}}}^{2}, \rho_{0} C_{\mathrm{p}} \overline{w^{\prime} \theta_{\mathrm{v}}^{\prime}}$ and the total momentum flux. This is expected as the shear forcing for SS resembles observations more closely than that for either WS or NS. The main deficiencies are the significantly larger in-cloud moisture flux and opposite meridional shear compared to observations.

Two main features emerge from both the observations and the LES results. First, there is a well-defined decoupled turbulence structure in terms of local minimum values below cloud base in all the second-moment turbulence statistics. Second, strong shear mixing near cloud top is indicated by a large momentum flux. Several key points can be drawn from the sensitivity simulations as follows: (1) the intense mixing in SS weakens the in-cloud turbulence intensity by reducing the cloud water, (2) the negative buoyancy flux at the cloud top is significantly augmented by the shear enhanced mixing, 
Table 2. Comparison between LES and observation results averaged in the cloud layer.

\begin{tabular}{|c|c|c|c|c|c|c|c|c|c|c|}
\hline $\begin{array}{l}\text { Cloud } \\
\text { Layer Avg. }\end{array}$ & $\begin{array}{l}\bar{\theta}_{1} \\
\mathrm{~K}\end{array}$ & $\mathrm{~g} \mathrm{~kg}^{\bar{q}_{\mathrm{t}}}$ & $\mathrm{g} \mathrm{kg}^{-1}{ }^{\bar{q}_{\mathrm{c}}}$ & $\begin{array}{r}\bar{u} \\
\mathrm{~ms} \mathrm{~s}^{-1}\end{array}$ & $\mathrm{~ms} \mathrm{~s}^{-1}$ & $\begin{array}{r}{\overline{w^{\prime}}}^{2} \\
\mathrm{~m}^{2} \mathrm{~s}^{-2}\end{array}$ & 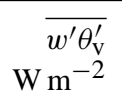 & $\begin{array}{r}{\overline{w^{\prime}}}^{3} \\
\mathrm{~m}^{3} \mathrm{~s}^{-3}\end{array}$ & $\begin{array}{r}\text { Stress } \\
\mathrm{N} \mathrm{m}^{-2}\end{array}$ & $\begin{array}{r}\overline{w^{\prime} q_{\mathrm{t}}^{\prime}} \\
\mathrm{W} \mathrm{m}^{-2}\end{array}$ \\
\hline OBS & 290.5 & 7.86 & 0.09 & 0.4 & -2.0 & 0.1 & 3 & -0.017 & 0.02 & 8.0 \\
\hline SS & 290.2 & 7.87 & 0.15 & 5.1 & -0.5 & 0.09 & 4.2 & -0.005 & 0.03 & 21.8 \\
\hline WS & 290.0 & 7.98 & 0.23 & 2.5 & 0.9 & 0.11 & 8.8 & -0.013 & 0.015 & 21.3 \\
\hline NS & 289.9 & 7.98 & 0.27 & 0 & 0.0 & 0.14 & 11.2 & -0.020 & 0.004 & 17.3 \\
\hline
\end{tabular}

and (3) the cloud cellular structure is suppressed by the enhanced mixing in SS.

\section{Inversion layer}

Because the wind shear directly affects the dynamic stability of the inversion, its effect can have important implications on the turbulence in this layer and the overall stratocumulustopped MBL structure. This section focuses on the entrainment zone by comparing flow characteristics among different simulations. To represent the stability, we use three different types of Richardson number. For discussions of vertical turbulence profiles, the gradient Richardson number is used, which is defined by

$R i=\frac{g}{\bar{\theta}} \cdot \frac{\partial \bar{\theta}_{\mathrm{vl}} / \partial z}{\left[\left(\frac{\partial \bar{u}}{\partial z}\right)^{2}+\left(\frac{\partial \bar{v}}{\partial z}\right)^{2}\right]}$,

where $\theta_{\mathrm{vl}}=\theta_{\mathrm{l}}+0.608 T q_{\mathrm{t}}$. To characterize the overall dynamic stability of the whole flow within the inversion, we also use the bulk Richardson number defined by Turner (1973); that is

$R i_{\mathrm{b}}=\frac{g}{\bar{\theta}} \frac{\Delta \overline{\theta_{\mathrm{vl}}} \cdot \Delta z_{\mathrm{i}}}{\left[(\Delta \bar{u})^{2}+(\Delta \bar{v})^{2}\right]}$

where $\Delta()$ denotes a difference across the inversion layer thickness $\Delta z_{\mathrm{i}}$. It is commonly accepted that the critical value of $R i$ is 0.25 , below which the flow becomes turbulent, although the suggestions in the literature range from 0.2 to 1.0 (Galperin et al., 2007). For the boundary layer flow with $R i$ between 0.25 and 1 , intermittency turbulence may dominate at a moderate level (Sun et al., 2011).

If the mean variables in Eq. (1) are replaced by the grid values without any averaging, the resulting $R i$ is designated as the instantaneous local Richardson number $R i_{1}$. This local Richardson number can also be used to describe the flow stability (i.e., Moeng et al., 2005). It will be used here in discussions of probability density function (PDF) of turbulent perturbations within the inversion layer.

We first compare the variances of $\theta_{\mathrm{l}}, q_{\mathrm{c}}$, and $R i$ within the inversion in Fig. 5, which exhibit three important features. First, the inversion layer thickness increases with increasing
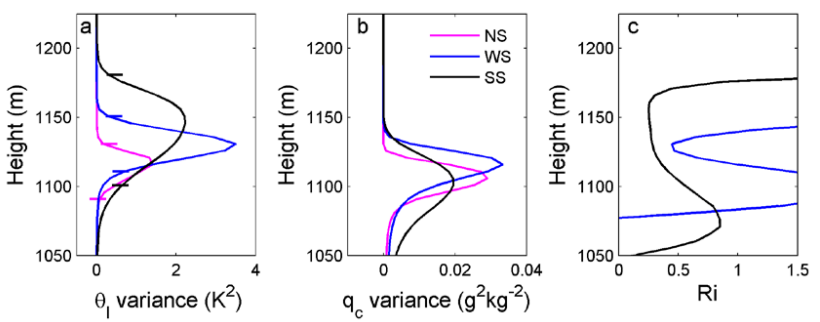

Fig. 5. Profiles of scalar variances and the gradient Richardson number within the inversion. (a) $\overline{\theta_{1}^{\prime 2}}$; (b) $q_{\mathrm{c}}^{\prime 2}$; and (c) $R i$ (its values from NS are ill-defined, and therefore not presented here). The horizontal bars in (a) denote the levels of $z_{\text {itop }}$ and $z_{\text {ibase }}$ for each simulation. See text for the definition of these levels.

shear forcing, ranging from $30 \mathrm{~m}$ for NS to $80 \mathrm{~m}$ for SS. Second, the cloud-top height, which can be easily diagnosed by the diminishing $\overline{q_{\mathrm{c}}^{\prime 2}}$, does not reach to the top of the inversion layer as shown in Fig. 5a and b. There clearly exists a finite cloud-free sublayer in the upper part of the inversion for each run. The sublayer thickness is the largest for SS and diminishes for NS. Third, $R i$ from SS is significantly smaller than that from WS. The former tends to approach 0.25 between $1120 \mathrm{~m}$ and $1170 \mathrm{~m}$ where a large $\overline{\theta_{1}^{\prime 2}}$ is present. This leads to a quasi-constant $R i$ layer $50 \mathrm{~m}$ thick in the SS case. It appears that a critical and equilibrium $R i(\sim 0.25)$ is reached at these levels for the SS case.

We next examine the bulk characteristics of the inversion layer. For this purpose, we compute the bulk Richardson number $\left(R i_{\mathrm{b}}\right)$ across the thickness of the inversion layer following Eq. (2). That is, $\Delta z_{\mathrm{i}}=z_{\text {itop }}-z_{\text {ibase }}$, where $z_{\text {itop }}$ is the level of the inversion layer top and $z_{\text {ibase }}$ the level of the inversion layer base. All other vertical differences are also defined at these two levels. Because the vertical gradient of $\overline{\theta_{\mathrm{vl}}}$ increases significantly at the inversion base and decreases at the top, $z_{\text {itop }}$ can be defined as the level at which the second derivative of $\overline{\theta_{\mathrm{vl}}}$ is a local minimum, whereas $z_{\text {ibase }}$ is the level at which it is a local maximum. We also calculate the cloud top height $\left(z_{\text {ctop }}\right)$, which is defined as the level above which the cloud fraction falls below $0.5 \%$.

Figure 6 shows the temporal evolutions of $z_{\text {itop}}, z_{\text {ibase}}$, $z_{\text {ctop }}$, the overall wind shear (defined by $\sqrt{(\Delta \bar{u})^{2}+(\Delta \bar{v})^{2}}$ ), and $R i_{\mathrm{b}}$. The stair-stepped appearance of the curves is due to 

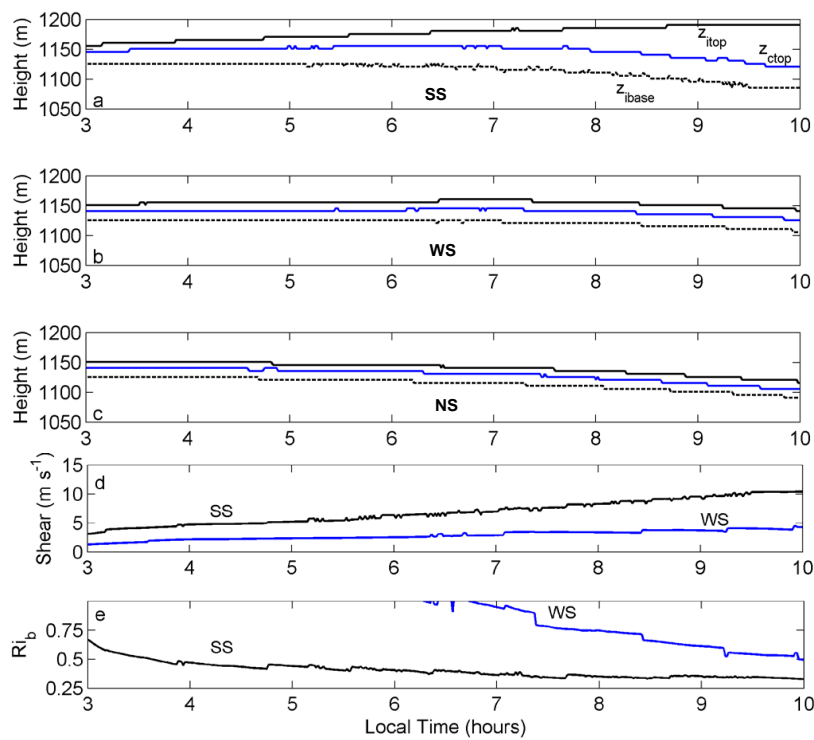

Fig. 6. Temporal evolutions of the inversion layer characteristics. (a-c) Evolution of the inversion top $z_{\text {itop }}$ (solid black curve), inversion base $z_{\text {ibase }}$ (dashed black) and cloud-top heights $z_{\text {ctop }}$ (blue lines); (d) the overall wind shear $\left(\sqrt{(\Delta \bar{u})^{2}+(\Delta \bar{v})^{2}}\right)$ with black curve for SS and blue for WS; and (e) the bulk Richardson number $R i_{\mathrm{b}}$ with the black for SS and blue for WS. The wind shear from SN is zero and $R i_{\mathrm{b}}$ is ill-defined; they are not presented here.

the fact that these heights are defined at the grid levels and no interpolation is performed. For the SS case, the enhanced turbulent mixing within the inversion results in the highest $z_{\text {itop }}$ and lowest $z_{\text {ibase }}$. Consequently, the thickness of the inversion layer $\left(\Delta z_{\mathrm{i}}=z_{\text {itop }}-z_{\text {ibase }}\right)$ reaches approximate $110 \mathrm{~m}$ at the end of the SS simulation compared to only $40 \mathrm{~m}$ for the WS and $30 \mathrm{~m}$ for the NS cases. A cloud-free sublayer is present in the upper inversion for all the simulations. But the sublayer from SS has the greatest thickness of approximate $60 \mathrm{~m}$ at the end of simulation; it is significantly larger than those from WS and NS, which are $20 \mathrm{~m}$ and $10 \mathrm{~m}$, respectively.

The inversion layer thickness is determined by the turbulent mixing, regulated strongly by the dynamic stability. Smaller $R i_{\mathrm{b}}$ tends to promote stronger turbulence mixing, producing a thicker $\Delta z_{\mathrm{i}}$. This relationship can be clearly seen by comparing $\Delta z_{\mathrm{i}}$ and $R i_{\mathrm{b}}$ from different cases. For example, $\Delta z_{\mathrm{i}}$ is $110 \mathrm{~m}$ with a value of $R i_{\mathrm{b}}$ close to 0.33 for the SS case at the end of the simulation, while $\Delta z_{\mathrm{i}}$ is $40 \mathrm{~m}$ with the $R i_{\mathrm{b}}$ close to 0.5 for WS. It is notable that $R i_{\mathrm{b}}$ of SS decreases, but tends to stay slightly above 0.3 for last $3 \mathrm{~h}$ despite an increase in the overall wind shear $\sqrt{(\Delta \bar{u})^{2}+(\Delta \bar{v})^{2}}$ (Fig. 6d) and $\Delta z_{\mathrm{i}}$. The phenomenon that an equilibrium bulk Richardson number can be reached with increasing wind shear have been studied by a number of authors as highlighted in the introduction section. For example, Conzemius and Fedorovich (2006) argue that the equilibrium value of $R i(0.25)$ reached in their study points to a balance between shear production and buoyancy consumption of TKE for a clear sheared convection regime. In other LES simulations, the Kelvin-Helmholtz instability is developed within the thin inversion layer with a slightly larger $R i$-value of 0.5 (Kim et al., 2003). For stratocumulus clouds, a similar equilibrium $R i(\sim 0.3)$ is also found in a LES study using a strong wind shear case along the central coast of California by Wang et al. (2008).

These results suggest that there exists a feedback mechanism between the large-scale conditions and turbulence mixing through the inversion stability. The large-scale subsidence and radiative cooling near the cloud top tends to create a sharp inversion with a strong dynamic stability, whereas wind shear acts to destabilize the inversion. When the shear is sufficiently intense such that $R i_{\mathrm{b}}$ (or $R i$ ) approaches the critical value (e.g., 0.25 ), the turbulence is significantly enhanced with an increased $\Delta z_{\mathrm{i}}$, leading to a slightly larger $R i_{\mathrm{b}}$ (or $R i$ ). Eventually, an equilibrium $R i_{\mathrm{b}}$ (or $R i$ ) is reached. Through this process, the MBL height increases with a thicker inversion layer. It is notable that the equilibrium value for $R i_{\mathrm{b}}$ is different from that for $R i$ from SS. The difference is probably due to the different definitions and the nonlinear effect of the shear from Eqs. (1) and (2).

It is interesting to note that the mean shear of WS across the inversion $\left(\mathrm{SH}=\sqrt{(\Delta \bar{u})^{2}+(\Delta \bar{v})^{2}} / \Delta z_{\mathrm{i}} \approx 0.012 \mathrm{~s}^{-1}\right)$ is slightly greater than that of $\mathrm{SS}\left(\mathrm{SH} \approx 0.01 \mathrm{~s}^{-1}\right)$ for last $1.5 \mathrm{~h}$, even though the overall shear of SS is significantly stronger as shown in Fig. 6d. It occurs because the shear of WS is concentrated within a considerably smaller $\Delta z_{\mathrm{i}}$ under the weak shear forcing such that the mean thermal stability $\left(\Delta \overline{\theta_{\mathrm{vl}}} / \Delta z_{\mathrm{i}}\right)$ dominates the shear term in $R i_{\mathrm{b}}$, whose value is larger for WS than that for SS. Therefore, it is the bulk or gradient Richardson number that has a more fundamental control of the turbulent mixing within the inversion layer.

Because of the importance of the dynamic stability to the turbulent mixing, flow characteristics in the inversion can be explored using the instantaneous local Richardson number $R i_{1}$. Since a cloud-free sublayer is present within the inversion layer we specifically chose a level within this sublayer for each case for a comparison analysis. These levels are determined by examining the $\bar{\theta}_{1}$ and cloud fraction profiles (Fig. 7b and c); they are marked in Fig. 7b. Even though the $R i_{1}$ PDF may strongly depend on the level chosen as indicated by the $R i$ profiles in Fig. 5c, its comparison among the simulations provides an example of how the turbulence being controlled by the dynamic stability in the cloud-free sublayer.

The calculated $R i_{1}$ PDFs are shown in Fig. 7a. Because the mean wind speed is zero in NS, $R i_{1}$ is very large with a mean of $\sim 200$, and a broad distribution. Therefore, the PDF from NS is not displayed in Fig. 7a. For SS, the PDF peaks near the $R i_{1}$ value of 0.25 with a narrow distribution, whereas for WS it peaks near the $R i_{1}$ of 0.85 with a broader distribution. If the flow with $R i_{1}$ less than 0.25 is considered locally unstable 

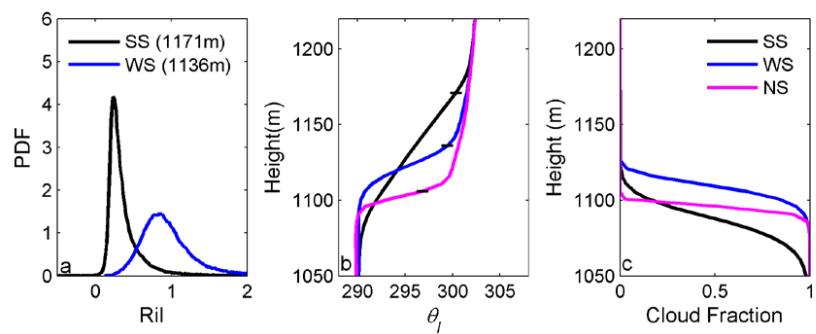

Fig. 7. Characteristics of the inversion layer. (a) PDF of the instantaneous local Richardson number $R i_{1}$; (b) $\bar{\theta}_{1}$ profile; and (c) cloud fraction profile. The levels at which the PDF are derived are denoted by horizontal bars on the corresponding $\theta_{1}$ profiles. These levels are within the cloud-free sublayers as seen from the $\bar{\theta}_{1}$ and cloud fraction profiles. The NS $R i_{1}$ PDF is not shown due to its large mean value $(\sim 200)$ and very broad distribution.

(Moeng et al., 2005), we can estimate the fractional coverage of the turbulent flows based on the $R i_{1}$ PDF. This fraction for SS, WS and NS is $0.3,0.002$, and 0 , respectively. If we relax the critical Richardson number to one (Galperin et al., 2007), the fraction is $0.96,0.63$ and $0.5 \times 10^{-3}$. This means that $96 \%$ of the flow is potentially turbulent for SS. This ratio is approximate $63 \%$ for WS and nearly zero for NS.

We further examine how the local flow variability depends on the inversion stability using the joint PDF of $R i_{1}$ with $w^{\prime}$, $\theta^{\prime}$ and $q_{\mathrm{v}}^{\prime}$ in the cloud-free sublayer in Fig. 8. Large variations for these three variables occur near 0.25 of $R i_{1}$ for SS, 0.85 for WS because the $R i_{1}$ PDF is maximized at these values (Fig. 7a). The variability from SS is significantly larger than that from WS due to a local environment that is dynamically less stable for the former than for the latter. It is noteworthy that negative $q_{\mathrm{v}}^{\prime}$ and positive $\theta^{\prime}$ are more associated with larger $R i_{1}$, suggesting that these fluctuations are strongly influenced by the entrained drier and warmer air. Their variability is also considerably suppressed by the stronger dynamic stability in the $R i_{1}$ range of 0.5 to 1.5 from SS and WS. The local Richardson number $R i_{1}$ from NS starts at approximate 0.8 at the lower end. Its joint PDF values at small $R i_{1}$ are approximately one to two order of magnitude lower than those from SS or WS as shown in Fig. 8. The vertical motion is week $\left(<0.12 \mathrm{~m} \mathrm{~s}^{-1}\right)$, indicating extremely week or no turbulence at all at this level for NS. These joint PDFs demonstrate that local flow characteristics within the inversion layer strongly depend on the instantaneous local Richardson number.

The wind shear reduces the dynamical stability of the inversion in an otherwise thermodynamically very stable environment. This reduction may enhance turbulent mixing within the inversion layer, leading to an increase in its thickness and creating a finite turbulent and cloud-free sublayer separating the MBL top and the cloud top. These LES results in general agree with the detailed observation analysis by Katzwinkel et al. (2011). Their analysis shows that the in-
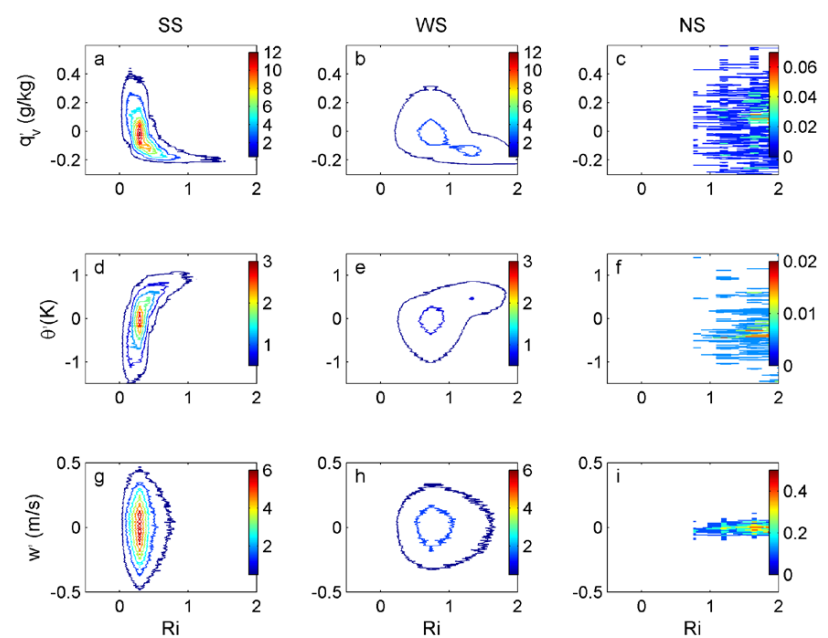

Fig. 8. Joint PDF of $R i_{1}$ with other variables $\left(q_{\mathrm{v}}, \theta\right.$ and $\left.w\right)$ in the cloud-free sublayer. The first column is for SS; the second WS and the third NS. The first row presents $R i_{1}-q_{\mathrm{v}}^{\prime}$ joint PDF; the second $R i_{1}-\theta^{\prime}$; and the third $R i_{1}-w^{\prime}$.

version layer is turbulent with $R i$ ranging between 0.2 to 0.7 and the depth of the cloud-free sublayer between $37 \mathrm{~m}$ and $85 \mathrm{~m}$.

\section{Entrainment rate and decoupling}

An important common feature of the above simulations is the decoupled turbulence structure as shown in Fig. 3; that is, a minimum is present just below clouds in each of the three turbulent flux profiles (i.e. ${\overline{w^{\prime}}}^{2}, \rho_{0} L \overline{w^{\prime} q_{\mathrm{t}}^{\prime}}, \rho_{0} C_{\mathrm{p}} \overline{w^{\prime} \theta_{\mathrm{v}}^{\prime}}$ ). What causes the decoupling? It is well known that the cloud solar absorption tends to stabilize the MBL and decouple the cloud from the subcloud layer (Nicholls, 1984). Another possible contributing process is the wind shear, because it tends to enhance the entrainment mixing. Therefore, it is natural to ask: what is the effect of the wind shear on the decoupling, and can the shear alone decouple the MBL (e.g., during nights)? To answer these questions, we perform three additional simulations, SSN, WSN, and NSN, which exclude the solar radiation and use the same shear conditions as those in the first set of three cases (SS, WS and NS).

Before proceeding to analyze the decoupling, we provide more evidence from the simulations that strong shear forcing indeed enhances the entrainment. For this purpose, the entrainment velocity, $w_{\mathrm{e}}$, is calculated from

$w_{\mathrm{e}}=\frac{\mathrm{d} z_{\text {itop }}}{\mathrm{d} t}+D \cdot z_{\text {itop }}$

where $D$ is the large-scale divergence listed in Table 1 . The computed $w_{\mathrm{e}}$ together with $R i_{\mathrm{b}}$ and the inversion thickness $\left(\Delta z_{\mathrm{i}}\right)$ are summarized in Table 1. 
The inversion layer thickness $\left(\Delta z_{\mathrm{i}}\right)$ increases with shear forcing, and the no-shear cases (i.e., NS and NSN) have the minimum values among the simulations. The minimum $R i_{\mathrm{b}}$ is reached in the SS simulation where there is a strong shear as well as a weakened temperature gradient due to the solar absorption warming in the cloud layer. There is a general trend of higher $\Delta z_{\mathrm{i}}$ being correlated with lower values of $R i_{\mathrm{b}}$, although the relationship is not monotonic. Especially noteworthy is the result (column $w_{\mathrm{e}}$ and $R i_{\mathrm{b}}$ in Table 1) that the entrainment rate $w_{\mathrm{e}}$ increases with decreasing $R i_{\mathrm{b}}$ for both the solar simulations (SS, WS and NS) and the no-solar (SSN, WSN, NSN), suggesting that $w_{\mathrm{e}}$ is inversely proportional to $R i_{\mathrm{b}}$ or $R i$. This is expected as a similar relationship is used for $w_{\mathrm{e}}$ and the buoyancy-determined bulk Richardson number (e.g., Turton and Nicholls, 1987). Since there is only limited variety of the shear and thermal stability in these simulations, no attempt is made in this study to seek a functional relationship of $w_{\mathrm{e}}$ or $\Delta z_{\mathrm{i}}$ in terms of $R i_{\mathrm{b}}$.

The shear-enhanced entrainment considerably affects the turbulence structure as shown in Fig. 9. The maximum buoyancy flux $\left(\rho_{0} C_{\mathrm{p}} \overline{w^{\prime} \theta_{\mathrm{v}}^{\prime}}\right)$ is consistently weakened with increasing shear forcing. The buoyancy flux minimum just below clouds decreases in this weakening process and approaches zero in the SSN compared to $17 \mathrm{~W} \mathrm{~m}^{-2}$ from the NSN case. This difference in the minimum value between SSN and NSN is significantly larger than that between SS and NS (Fig. 3e), suggesting that the solar warming has in part concealed the shear effect in the cloud layer. Being consistent with the $\rho_{0} C_{\mathrm{p}} \overline{w^{\prime} \theta_{\mathrm{v}}^{\prime}}$ profiles, ${\overline{w^{\prime}}}^{2}$ is reduced considerably with intensifying shear forcing. It obtains a local minimum just below the cloud base for the strongest shear case (SSN). The minimum in $\overline{w^{\prime}}$ leads to a non-linear total water flux $\left(\rho_{0} L \overline{w^{\prime} q_{\mathrm{t}}^{\prime}}\right)$ profile, resulting in a larger drying tendency for the cloud layer than for the subcloud layer. Although the $\rho_{0} L \overline{w^{\prime} q_{\mathrm{t}}^{\prime}}$ profile from either WSN or NSN is clearly linear, the former has a larger drying tendency than the latter, as shown in Fig. 9c, indicative of enhanced entrainment for WSN.

The shear enhanced mixing also affects the MBL heat budget represented by the heat $\left(\rho_{0} C_{\mathrm{p}} \overline{w^{\prime} \theta_{1}^{\prime}}\right)$ and radiative fluxes shown in Fig. 9d and e. The magnitude of the entrainment heat flux substantially increases due to the enhanced mixing, whereas the in-cloud heat flux decreases due to the reduced radiative cooling - this reduction is also seen in Fig. 3e. In general, the entrainment warming increases and eventually dominates the radiative cooling with increasing shear forcing. To quantify this change in the heat budget, we calculate the ratio of the entrainment warming to the total radiative cooling in the MBL, i.e., $\Delta F_{\theta} / \Delta F_{\mathrm{R}}$, where $\Delta$ denotes the difference between the most negative buoyancy level and the surface. This ratio was used by Stevens et al. (2005) to evaluate the decoupling process and the values calculated from our simulations are listed in Table 1. It is seen that the ratio obtains the maximum value (1.2) for SSN and the smallest for NSN (0.6). A value larger than one implies that the en-
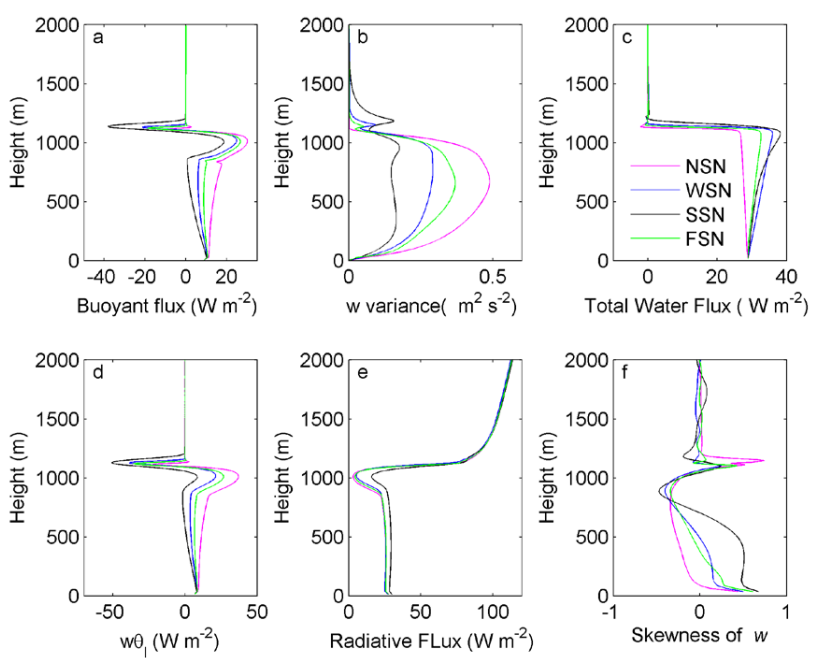

Fig. 9. Profiles of turbulence variables for four no-solar simulations. (a) $C_{\mathrm{p}} \rho_{0} \overline{w^{\prime} \theta_{\mathrm{v}}^{\prime}}$; (b) $\overline{w^{\prime 2}}$; (c) $L \rho_{0} \overline{w^{\prime} q_{t}^{\prime}}$; (d) $C_{\mathrm{p}} \rho_{0} \overline{w^{\prime} \theta_{1}^{\prime}}$; (e) Longwave radiative flux; and (f) skewness of $w$, defined by $\frac{1}{w^{\prime 3}} / \sigma_{w}^{3 / 2}$ where $\sigma_{w}$ is the standard deviation of $w$.

trainment warming is greater than the radiative cooling, suggesting that the decoupling is likely to occur. The maximum ratio for SSN (1.2) is close to, but below the critical value (1.35) for decoupling proposed by Stevens et al. (2005). For NSN, the radiative cooling is clearly the dominant driving force since the ratio is only 0.6 . The other two weak shear cases (WSN and FSN) have significant entrainment warming, although the ratio does not go above one.

The decoupling process in the strong shear case (SSN) should also be reflected in the mean temperature and moisture profiles. As shown in Fig. 10, the MBL becomes warmer and drier with increasing entrainment. More importantly, the gradients of both $\bar{\theta}_{\mathrm{l}}$ and $\bar{q}_{\mathrm{t}}$ at the cloud base for SSN develop and become distinctively different from other cases. This further confirms that the cloud layer becomes partially decoupled from the subcloud layer for this case, even though the degree of decoupling appears to be relatively weak since there is no significant decrease in the cloudiness.

The skewness of $w$ gives a dimensionless measure of asymmetry of the PDF. Figure $9 \mathrm{f}$ shows that there is no significant difference in the skewness in the cloud layer between the shear and shear-free cases even though the magnitude of ${\overline{w^{\prime}}}^{3}$ decreases with increasing shear forcing (not shown here but can be inferred from Fig. 3i). Consequently, the reduced ${\overline{w^{\prime}}}^{3}$ for the shear cases is mainly due to a weaker turbulence intensity, i.e., ${\overline{w^{\prime}}}^{2}$, instead of the asymmetry of the distribution.

One important feature of the strong shear effect is a simultaneous increase in the TKE buoyant consumption near the inversion, and decrease in the buoyant production in the cloud layer. This feature significantly contributes to the 

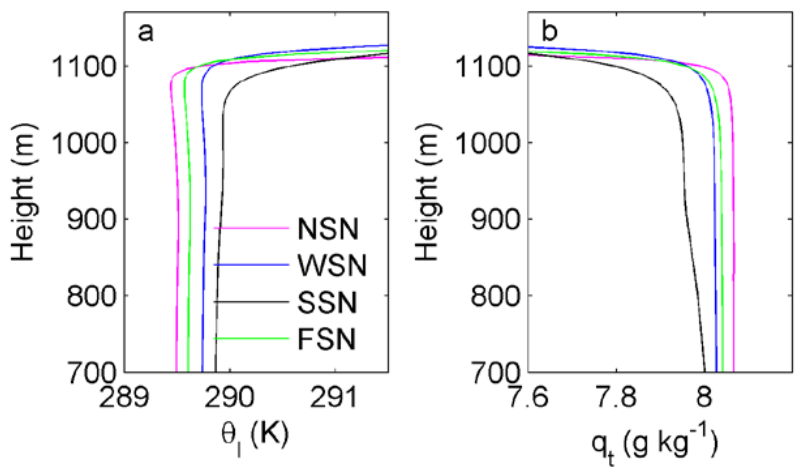

Fig. 10. Mean profiles for no-solar simulations. (a) $\bar{\theta}_{\mathrm{l}}$; and (b) $\bar{q}_{\mathrm{t}}$.

decoupling process, because both the intense entrainment warming and weak in-cloud turbulence tend to accumulate heat in the cloud layer, leading to different heating rates between the cloud and the subcloud layer. A useful parameter for quantifying this feature is the ratio of the integrated buoyant consumption to the production, defined as

$$
A=\frac{-\int_{0}^{z_{\text {itop }}} \overline{w^{\prime} \theta_{\mathrm{v}}^{\prime}}(<0) \mathrm{d} z}{\int_{0}^{z_{\text {itop }}} \overline{w^{\prime} \theta_{\mathrm{v}}^{\prime}}(>0) \mathrm{d} z} .
$$

This ratio is used in mixed-layer models for parameterization of stratocumulus clouds (e.g., Randall, 1984). The larger the ratio $A$ becomes, the more dominant the entrainment warming is and the more likely decoupling occurs. As shown in Table 1, the ratio $A$ is 0.39 for SSN which is much larger than 0.014 for NSN. This suggests that the turbulence is not strong enough (i.e., the weak buoyant production) to redistribute the overwhelming entrainment warming (i.e., the large buoyant consumption) in the SSN case. The weak shear cases produce the $A$-values that are between 0.034 and 0.14 , markedly smaller than that from the strong shear cases. It implies that the strong turbulence can efficiently redistribute the entrained warm air such that a well-mixed layer is maintained. Another version of the ratio $A$, focusing on the buoyant consumption in the subcloud layer, is developed with mixed-layer models by Turton and Nicholls (1987) and Bretherton et al. (1997) (also see Stevens, 2000). They argue that the ratio needs to be in the range of 0.15-0.4 for decoupling to occur. The result presented here is different from theirs as the SSN results do not clearly show negative buoyancy flux in the subcloud layer.

So far, all the shears included in the simulations are driven by the large-scale baroclinicity associated with the sloping MBL. Another common mechanism of wind shears is surface friction under a barotropic boundary layer condition. These two types of wind shear should have similar dynamic effects on the MBL as they exert a similar control on the in- version layer stability. To confirm this hypothesis, we further perform another simulation with a wind shear driven by the surface friction. Since the observed surface stress is small due to weak surface winds, we intentionally increase the observed stress by a factor of 5 to produce a noticeable wind shear across the inversion. This simulation is designated as FCN and listed in Table 1. The final overall wind shear across the inversion for this case is $\Delta \bar{u} \sim-2 \mathrm{~m} \mathrm{~s}^{-1}$ and $\Delta \bar{v} \sim 3.5 \mathrm{~m} \mathrm{~s}^{-1}$, a slightly weaker than that in WS. The turbulence profiles of FSN stay between those of SSN and NSN, exhibiting weaker turbulence intensity and buoyancy forcing, and a larger moisture flux in the cloud layer than those of NSN (Fig. 9).

The shear-enhanced entrainment mixing inevitably impacts the buoyantly driven convective circulation within stratocumulus clouds, since it reduces the turbulence buoyant production. To examine the effect, we conditionally sample the LES data from the no-solar simulations using one standard deviation of $w\left(\sigma_{w}\right)$ to select convective updraft or downdraft grid points. That is, a grid point is defined as part of updrafts (or downdrafts) if $w \geq \sigma_{w}$ (or $w \leq-\sigma_{w}$ ). We then calculate averaged perturbations for variables of updrafts and downdrafts; they are defined as the averaged updowndraft variables minus the ensemble means (e.g., $\theta_{\mathrm{vu}}^{\prime}=$ $\theta_{\mathrm{vu}}-\bar{\theta}_{\mathrm{v}}$, where the subscript $u$ denotes a updraft-averaged variable).

The buoyancy and vertical motion perturbations along with the corresponding standard deviations are shown in Fig. 11 to assess the change in the circulation due to wind shear. The buoyancy perturbations in updrafts $\left(\theta_{\mathrm{vu}}^{\prime}\right)$ and downdrafts $\left(\theta_{\mathrm{vd}}^{\prime}\right)$ in clouds are consistently reduced with increasing wind shear. For SSN, both $\theta_{\mathrm{vu}}^{\prime}$ and $\theta_{\mathrm{vd}}^{\prime}$ are nearly zero just below clouds, compared with the larger magnitudes $(\sim 0.04 \mathrm{~K}$ and $0.02 \mathrm{~K})$ for NSN and WSN. Near cloud tops, driven by radiative cooling, $\theta_{\mathrm{vu}}^{\prime}$ and $\theta_{\mathrm{vd}}^{\prime}$ of SSN obtain their local maximum $(\sim 0.04 \mathrm{~K})$ that is smaller than that of NSN $(0.07 \mathrm{~K})$ and WSN $(0.05 \mathrm{~K})$. A weakened convective circulation is clearly indicated by the slowed updraft $\left(w_{\mathrm{u}}^{\prime}\right)$ and downdraft $\left(w_{\mathrm{d}}^{\prime}\right)$ motions. Magnitudes of these perturbations are consistent with the variability measured by the standard deviations. The largest difference in $\sigma_{\theta_{\mathrm{v}}}$ among the simulations occurs just below the cloud base where its values for SSN and WSN are smaller than those of NSN. The $\sigma_{w}$ magnitude decreases with increasing wind shear among these cases. The difference is more notable in the subcloud layer. The impacts on the convective circulation are mainly driven by the different radiative cooling rates since it is the main driving force for the convection as discussed by Nicholls (1989).

It can be concluded that the intense wind shear indeed causes the cloud layer being decoupled from the subcloud layer in the SSN simulation. Even though the shear does not lead to decoupling for the WSN (or FSN) case, it nevertheless enhances the entrainment. The entrainment mixing is 
enhanced by the weakened inversion stability represented by $R i$ due to wind shear. The enhanced entrainment increases the negative buoyancy flux which dominates the radiative cooling in SSN. In the two shear forcing cases (WSN and SSN), positive buoyancy flux within and just below the clouds decrease markedly compared to that of the shear-free case (NSN). This occurs mainly because the enhanced mixing near the cloud top reduces the cloud water, leading to a reduction in the radiative cooling. The enhanced entrainment also introduces more buoyant air to clouds so that the buoyancy flux is further reduced below clouds. Combination of the enhanced entrainment warming and reduction in the radiative cooling leads to decoupling.

It should be emphasized that the impact of the shear on the entrainment may depend on many characteristics of the MBL other than the dynamic stability. For example, a weaker inversion with a strong wind shear may result in a decrease in the entrainment rate as result of significantly weakened positive buoyancy flux as shown in Wang et al. (2008). Recently, Katzwinkel et al. (2011) showed that $w_{\mathrm{e}}$ decreases with an increase in the sublayer thickness caused by the enhanced shear with observations, which appears different from our results. Although the current study is not comprehensive enough to address these issues, more detailed numerical modeling and observational studies are clearly needed to provide new insights in the entrainment mixing process under strong wind shear conditions.

\section{Summary}

Wind shear exists across the inversion most of the time in the stratocumulus-topped MBL, either due to surface friction or baroclinicity associated with the sloping MBL. Despite the difference in their causes, both types of wind shear strongly influence the dynamic stability of the inversion layer, which can be measured by the gradient Richardson number. Therefore, the wind shear may significantly affect the cloud-top entrainment, as well as the turbulence structure of stratocumulus convection. While the importance of wind shear is well recognized, there have been only a few focused studies on sheared stratocumulus convection. In this study, we examine the impact of the wind shear on the turbulence structure using LES simulations and sensitivity experiments based on observations from the Twin-Otter RF18 during VOCALS-REx.

Two sets of simulations have been performed. The first experiment set uses different wind shear forcing [i.e., strong shear (SS), weak shear (WS) and no shear (NS)] and includes solar radiation calculation for comparison with the observations. The wind shear forcing strength is specified using the vertical gradient of the geostrophic wind across the inversion that represents part of the large-scale forcing. To isolate the shear effect from that of cloud solar absorption, a second set of simulations is performed; they exclude the solar radiation calculation, but have the same shear forcing conditions (i.e.
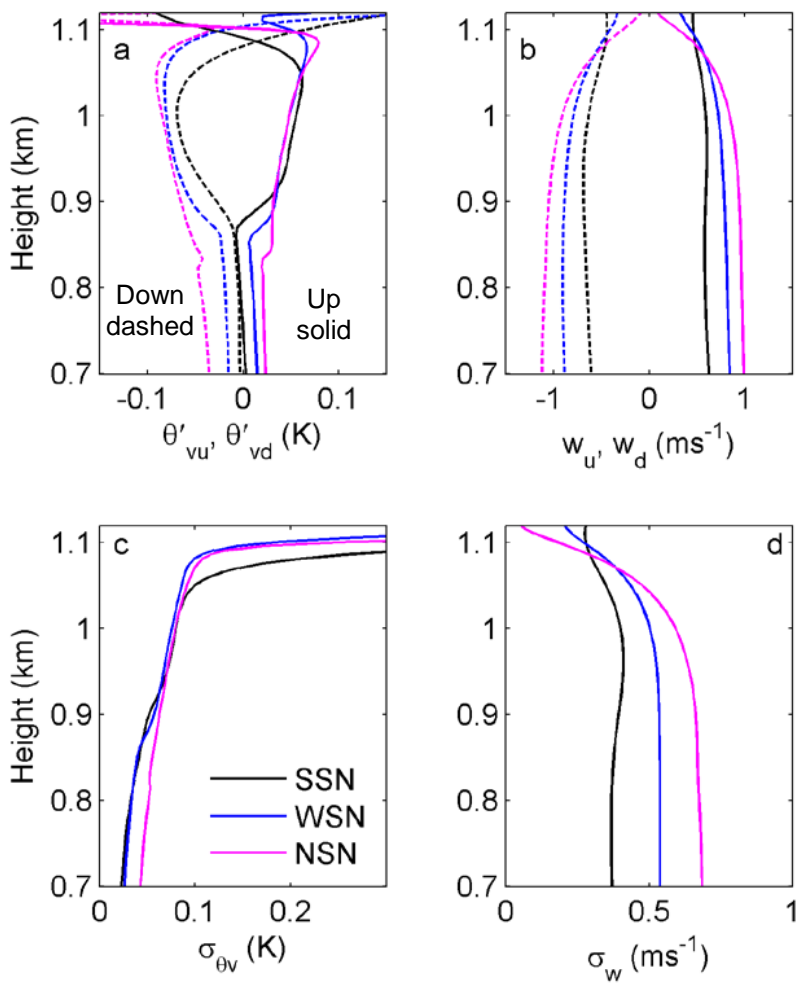

Fig. 11. Updraft-downdraft variables of convective circulation for no-solar simulations. (a) Averaged perturbations of buoyancy; (b) averaged updraft and downdraft velocity; (c) $\sigma_{\theta \mathrm{v}}$; and (d) $\sigma_{w}$.

SSN, WSN, and NSN in Table 1). An additional simulation (FSN) is also performed to assess the wind shear forced by the surface friction under barotropic conditions.

The comparison analysis shows a reasonable agreement between the observations and the SS simulation with solar radiation. Decoupling is clearly seen in both the observed and modeled turbulence structures characterized by a local minimum below clouds for the fluxes such as ${\overline{w^{\prime}}}^{2}, \rho_{0} L \overline{w^{\prime} q_{\mathrm{t}}^{\prime}}$, and $\rho_{0} C_{\mathrm{p}} \overline{w^{\prime} \theta_{\mathrm{v}}^{\prime}}$ for all the cases. The shear-enhanced mixing is also indicated by similarly large momentum fluxes near the cloud top from both the SS simulation and observations.

Increased wind shear forcing may reduce the bulk Richardson number $\left(R i_{\mathrm{b}}\right)$ or gradient Richardson number $(R i)$ of the inversion layer, enhance the mixing, and therefore thicken the inversion layer. The bulk Richardson number $\left(R i_{\mathrm{b}}\right)$ appears to have a lower bound at an equilibrium value $\sim 0.3$. A quasi-constant $R i(\sim 0.25)$ layer of $50 \mathrm{~m}$ thickness within the inversion is also simulated in the SS case. This suggests that there exists a feedback mechanism between the large-scale conditions and turbulence mixing through the inversion dynamic stability. The role of the shear is to generate turbulence by destabilizing the inversion layer, whereas the turbulent mixing feeds back to ensure that a dynamically stable inversion is maintained. This is consistent with a number of previous observations and numerical simulations, which 
found an equilibrium bulk Richardson number is reached after large wind shear is applied (e.g., Turner, 1973; Conzemius and Fedorovich, 2006; Wang et al., 2008; and Katzwinkel et al., 2011).

The shear-enhanced mixing leads to a clear separation of the MBL top (where turbulence diminishes) from the cloud top (where cloud fraction goes to zero), creating a finite cloud-free sublayer in the upper inversion. This sublayer thickness increases with decreasing $R i_{\mathrm{b}}$. These results are, in general, consistent with recent observational studies by Katzwinkel et al. (2011). The wind shear may enhance the TKE buoyant consumption within the inversion, whereas it weakens the buoyant production in the cloud layer. Both effects tend to stabilize the stratocumulus-topped MBL. The no-solar simulations show that the intense wind shear (SSN) can result in a decoupling process, in which the minimum buoyancy flux in sub-cloud layer is close to zero and nonlinearity in the total water flux develops. In the weak shear forcing case (WSN) where no decoupling occurs, a decrease in the buoyancy flux in the sub-cloud layer and increase in the entrainment flux is apparent, indicative of an overall weakening of the turbulence buoyant production owing to wind shear. The entrainment rate is also shown to be a decreasing function of $R i_{\mathrm{b}}$, as a stronger inversion stability inhibits the turbulence mixing. Because of the change in the turbulence buoyant production, the convective circulation is also impacted by the enhanced shear mixing. Overall, the convection becomes weaker owing to the reduced buoyancy forcing. Specifically, the buoyancy forcing for the convective updown drafts in the subcloud layer is close to zero.

Results of this study highlight that the wind shear affects the turbulence structure of the MBL by changing the dynamic stability of the inversion, which is critical for the determination of the entrainment mixing. Therefore, $R i$ or $R i_{\mathrm{b}}$, as a measure of the inversion dynamic stability, should be considered as a key control parameter in the parameterization of the entrainment rate. Most of previous parameterizations use the convective velocity scale without including wind shear in the definition of bulk Richardson number (e.g., Grenier and Bretherton, 2000). It is likely that a bulk Richardson number based on a combination of wind shear and integrated buoyancy flux represents more accurately the dynamic stability of the inversion in entrainment parameterizations. This type of parameterization already has been developed for a sheared cloud-free convective boundary layer (e.g., Conzemius and Fedorovich, 2007).

Wind shear also contributes to the decoupling process, which plays a major role in the transition from overcast stratocumulus to scattered shallow cumulus clouds. Given same large-scale conditions such as the lower tropospheric stability and sea surface temperature, a cloud-topped MBL with a stronger wind shear across the inversion is likely more favorable for the decoupling to occur. Therefore, the shear effects on the decoupling and the cloud regime transition should be considered and further studied. These effects may be partic- ularly important for the MBL in the Southeast Pacific where the wind shear is persistent and relatively intense.

Acknowledgements. Shouping Wang has benefitted from many in-depth discussions with Qing Wang on wind shears over the years. We thank James Doyle for his valuable review of an early draft. We are also very grateful to the Twin Otter staff and crew for the unique and high quality dataset. Constructive comments made by Patrick Chuang and an anonymous reviewer improved the presentation of the manuscript. Shouping Wang and Qingfang Jiang were supported by the Office of Naval Research (ONR) under Program Element (PE) 0602435N. Xue Zheng was supported by ONR grant N000140810465 and the NOAA/CPPA Program under grant NA08OAR4320889. COAMPS is a registered trademark of the Naval Research Laboratory.

Edited by: R. Wood

\section{References}

Bott, A.: A positive definite advection scheme obtained by nonlinear renormalization of the advective fluxes, J. Atmos. Sci., 117, 1006-1015, 1989.

Bretherton, C. S. and Wyant M. C.: Moisture transport, lowertropospheric stability, and decoupling of cloud-topped boundary layers, J. Atmos. Sci., 54, 148-167, 1997.

Bretherton, C. S., Wood, R., George, R. C., Leon, D., Allen, G., and Zheng, X.: Southeast Pacific stratocumulus clouds, precipitation and boundary layer structure sampled along $20^{\circ} \mathrm{S}$ during VOCALS-REx, Atmos. Chem. Phys., 10, 10639-10654, doi:10.5194/acp-10-10639-2010, 2010.

Brost, R. A., Wyngaard, J. C., and Lenschow, D. H.: Marine stratocumulus layers. Part II: Turbulence budgets, J. Atmos. Sci., 39 , 818-836, 1982.

Chen, C. and Cotton, W. R.: The physics of the marine stratocumulus-capped mixed layer, J. Atmos. Sci., 44, 2940 2950, 1987.

Conzemius, R. J. and Fedorovich, E.: Dynamics of sheared convective boundary layer entrainment. Part I: Methodological background and large-eddy simulations, J. Atmos. Sci., 63, 11511178, 2006.

Conzemius, R. J. and Fedorovich, E.: Bulk models of the shear convective boundary layer: evaluation through large eddy simulations, J. Atmos. Sci., 64, 786-807, 2007.

De Roode, R. S. and Wang, Q.: Do stratocumulus clouds detrain? FIRE I data revisited, Bound-Layer Meteor., 122, 479491, 2007.

Deardorff, J. W.: Stratocumulus-capped mixed layers derived from a three dimensional model, Bound.-Layer Meteorol., 18, 495-527, 1980.

Fu, Q. and Liou, K.-H.: On the correlated k-distribution method for radiative transfer in nonhomogenous atmospheres, J. Atmos. Sci., 49, 2139-2156, 1992.

Golaz, J.-C., Wang, S., Doyle, J. D., and Schmidt, J. M.: COAMPS $^{\mathrm{TM}}$ LES: Model evaluation and analysis of second and third moment vertical velocity budgets, Bound.-Layer Meteorol., 116, 487-517, 2005. 
Grenier, H. and Bretherton, C. S.: A moist PBL parameterization for large-scale models and its application to subtropical cloudtopped marine boundary layers, Mon. Weather Rev., 129, 357377, 2011.

Katzwinkel, J., Siebert H., and Shaw, R. A.: Observation of a selflimiting, shear-induced turbulent inversion layer above marine stratocumulus, Bound.-Layer Meteorol., doi:10.1007/s10546011-9683-4, 2011.

Kim, S.-W., Park, S.-H., and Moeng, C.-H.: Entrainment processes in the convective boundary layer with varying wind shear, Bound.-Lay. Meteorol., 108, 221-245, 2003.

Lilly, D. K.: Models of cloud-topped mixed layers under a strong inversion, Q. J. Roy. Meteor. Soc., 94, 292-308, 1968.

Moeng, C.-H., Stevens, B., and Sullivan P. P.: Where is the interface of stratocumulus-topped PBL?, J. Atmos. Sci., 62, 2626-2631, 2005.

Nicholls, S.: The dynamics of stratocumulus: aircraft observations and comparisons with a mixed-layer model, Q. J. Roy. Meteor. Soc., 110, 784-820, 1984.

Nicholls, S.: The structure of radiatively driven convection in stratocumulus, Q. J. Roy. Meteor. Soc., 115, 487-511, 1989.

Galperin, B., Sukoriansky, S., and Anderson, Ph. S.: On the critical Richardson number in stably stratified turbulence, Atmos. Sci. Lett., 8, 65-69, doi:10.1002/asl.153, 2007.

Randall, D. A.: Buoyant production and consumption of turbulent kinetic energy in cloud-topped mixed layer, J. Atmos. Sci., 41, 402-413, 1984.

Stevens, B.: Cloud transitions and decoupling in shear-free stratocumulus-topped boundary layers, Geophys. Res. Lett., 27, 2557-2560, doi:10.1029/1999GL011257, 2000.

Stevens, B., Moeng C.-H., Ackerman, A. S., Bretherton, C. S., Chlond, A., de Roode, S., Edwards, J., Golaz, J.-C., Jiang, H., Khairoutdinov, M., Kirkpatrick, M. P., Lewellen, D. C., Lock, A., Muller, F., Stevens, D. E., Whelan, E., and Zhu, P.:: Evaluation of large-eddy simulations via observations of nocturnal marine stratocumulus, Mon. Weather Rev., 133, 1443-1461, 2005.
Sun, J., Mahrt, L., Banta, R. M., and Pichugina, Y. L.: Turbulence regimes and turbulence intermittency in the stable boundary layer during CASES-99, J. Atmos. Sci., 69, 338-350, 2011.

Turner, J. S.: Buoyancy effects in fluids, Cambridge University Press, 368 pp., 1973.

Turton, J. D. and Nicholls, S.: A study of the diurnal variation of stratocumulus using a multiple mixed layer model, Q. J. Roy. Meteorol. Soc., 113, 969-1009, 1987.

Yamaguchi, R. and Randall D. A.: Cooling of entrained parcels in a large-eddy simulation, J. Atmos. Sci., 69, 1118-1136, 2012,

Wang, S., Golaz, J.-C., and Wang, Q.: Effect of intense wind shear across the inversion on stratocumulus clouds, Geophys. Res. Lett., 35, L15814, doi:10.1029/2008GL033865, 2008.

Wang, S., O’Neill, L. W., Jiang, Q., de Szoeke, S. P., Hong, X., Jin, H., Thompson, W. T., and Zheng, X.: A regional real-time forecast of marine boundary layers during VOCALS-REx, Atmos. Chem. Phys., 11, 421-437, doi:10.5194/acp-11-421-2011, 2011.

Wood, R., Mechoso, C. R., Bretherton, C. S., Weller, R. A., Huebert, B., Straneo, F., Albrecht, B. A., Coe, H., Allen, G., Vaughan, G., Daum, P., Fairall, C., Chand, D., Gallardo Klenner, L., Garreaud, R., Grados, C., Covert, D. S., Bates, T. S., Krejci, R., Russell, L. M., de Szoeke, S., Brewer, A., Yuter, S. E., Springston, S. R., Chaigneau, A., Toniazzo, T., Minnis, P., Palikonda, R., Abel, S. J., Brown, W. O. J., Williams, S., Fochesatto, J., Brioude, J., and Bower, K. N.: The VAMOS Ocean-Cloud-AtmosphereLand Study Regional Experiment (VOCALS-REx): goals, platforms, and field operations, Atmos. Chem. Phys., 11, 627-654, doi:10.5194/acp-11-627-2011, 2011.

Zheng, X., Albrecht, B., Jonsson, H. H., Khelif, D., Feingold, G., Minnis, P., Ayers, K., Chuang, P., Donaher, S., Rossiter, D., Ghate, V., Ruiz-Plancarte, J., and Sun-Mack, S.: Observations of the boundary layer, cloud, and aerosol variability in the southeast Pacific near-coastal marine stratocumulus during VOCALSREx, Atmos. Chem. Phys., 11, 9943-9959, doi:10.5194/acp-119943-2011, 2011. 